\title{
Features of the value-meaning sphere of parents raising children with autism spectrum disorders
}

\author{
Irina Yumatova ${ }^{1, *}$, Elena Novokhatko ${ }^{1}$, Elena Shevyreva $^{1}$ and Elena Kapitanova ${ }^{2}$ \\ ${ }^{1}$ Southern Federal University, Rostov-on-Don,344006, Russia, \\ ${ }^{2}$ Rostov Institute of protection of the businessman, Rostov-on-Don, 344009, Russia
}

\begin{abstract}
The paper is devoted to the study of the meaning sphere of parents raising children with autism spectrum disorder (ASD). The relevance of the study is explained by the fact that the birth of a sick child radically changes the family's life, breaking the existing system of values, life-meaning orientations. The psychological support of such families, providing them with the psychological assistance should begin with the search for new life meanings, the adoption of new values. The article describes the results of a study of changes in the value meaning sphere of parents raising children with serious disabilities. The article contains an analysis of domestic and foreign studies of family psychology, issues of early childhood autism. There are the description of empirical data from the study of changes in the life-meaning orientations of parents after the birth of a child with ASD, presentation of the results of a comparative analysis of life-meaning orientations and values for both group of parents. As a result, possible ways of helping parents raising a child with autistic symptoms were outlined.
\end{abstract}

\section{Introduction}

Unfortunately, the number of children with developmental problems is currently growing. Children with autism spectrum disorder occupied a special place among them. According to the Centers for Disease Control and Prevention, the prevalence of ASD in the world varies at the level of $1-2 \%$, which ranges from 75 to 151 million people. Autism spectrum disorders (ASD) are included in the group of "developmental disorders", thereby emphasizing the early onset of this disorder, the first symptoms should be registered in a child under age of 3 . The diagnostic criteria for this diagnosis are: the lack of social interaction and social communication; the repetition and limitation in activity, structure of behavior or interests [1]. In January 2022, ICD-11 will enter into force, in which the criteria for ASD diagnosis will be: lack of social and communicative spheres, stereotypes and mannerisms.

The clinical picture of this diagnosis is extremely diverse. For example, this disorder can be seen both in children with mental disabilities and in gifted ones who demonstrate achievements in the fields of science or art. There is a wide range of manifestations of impaired communication skills, e.g. patients with Asperger's syndrome can produce a large amount of verbal production, but at the same time demonstrate other diagnostic symptoms of

\footnotetext{
*Corresponding author: iiyumatova@sfedu.ru
} 
ASD. We can observe a colossal variation in relation to sensory perception, from the constant search for sensory stimulation to its complete avoidance. Such a variety of levels and manifestations of ASD symptoms significantly complicates the diagnosis.

The modern society insists on their inclusion in the world of healthy children, which is impossible without the parents' participation. For sure, the main role in building optimal relations between a child with ASD and the outside world is assigned to the parents, in whose family such a special child appears. It is parents performs not only the main work on the development and socialization of their children, but also ensure their life in general. The colossal physical and emotional stress that parents constantly experience after the birth of a sick child results in serious psychological problems. Therefore, psychological support and psychological assistance are relevant both for children with developmental problems and for their parents.

There are many authors studying the problems of parents raising children with developmental disorders, including those with ASD, including I.I. Mamaichuk [2], E.M. Mastyukova, A.G. Moskovkina [3], I.Y. Levchenko [4], V.V. Tkacheva [4] and others. Traditionally, the works describe the attitude of parents to their children with a diagnosis of ASD $[5,6]$. It is noted that the structure of these attitudes is characterized by a mismatch between emotional, cognitive and behavioral components. Describing parents raising children with ASD, the authors point out their low self-esteem, a high degree of anxiety, guilt feeling, and a tendency to abandon their own interests and needs "in the name of the child" $[3,6,7]$. In recent years, the authors are increasingly interested in the quality of life of the parents themselves who raise children with ASD [8], marital relationships in such families [9]. Many studies are devoted to the study of the parents' experience of stress $[3,4,10]$. As this stress acts constantly over a long period of time, so it affects the health of parents and leads to personal deviations. The success of such families, among other things, depends on the ability of parents to cope with stress, on the personality traits of parents of children with developmental disabilities. Coping behavior is usually associated with adaptation, the availability of resources and personal development, well-being [11]. According to Mamaichuk, I.I., Shabanova, E.V [2], Vysotina, T.N. [5], parents of children with developmental disorders often have destructive types of psychological defenses, distortions of parental attitudes towards children. Raising a child with developmental disabilities is extremely difficult and demanding. Not all parents take this responsibility upon themselves. Some of them, having learned that their child will be handicapped, abandon it, fearing difficulties. Other parents, understanding all the responsibility and assessing all the consequences, take the child into the family. Such parents take an active life position in the upbringing of a special child, trying to make every effort to compensate for the child's defects. The most difficult situation is when the parents learn about the peculiarities of their child's development later, when the child is already part of the family, when a certain attitude has been developed towards it. I.e. there is a feature of the presence of prolonged stress in parents, while the mechanisms of the formation of personal resources remain poorly understood.

The adoption of a special child occurs gradually, following certain stages (denial, bargain, anger, depression, acceptance) [4, 12]. At passing the stages of adoption of the child, both parents and the child itself experience stress. Research in recent decades has greatly expanded the understanding of the family's impact on the social and emotional development of a "special" child. Problems of preparation or formation of parents' readiness to interact with children with disabilities are described in modern studies $[4,12,13]$, etc. Perhaps the effectiveness of overcoming difficulties in the life of parents are connected with the need to rethink their life situation, change the structure of value orientations, and search for new life meanings. According to Seligman M., Darling R. [12], N.L. Belopolskaya [15], a new reality begins for the parents from the moment of understanding the child's diagnosis. In is starting 
with the adoption of their new child. In connection with the above, it is relevant to study the features of self-awareness of parents raising a child with developmental disorders.

For this reason, the study of the features of self-awareness of parents raising a child with developmental disabilities remains quite relevant. According to the main provisions of the theory of meaning, it is meaning formations that determine the features of the relationship between the subject and the world $[16,17]$.

Considering the features of life-meaning orientations of parents raising children with ASD, it seems relevant to pay attention to the presence of meaning dissonance as a kind of cognitive dissonance arising in their value-semantic sphere [16]. Each person has a concept of a goal, an ideal for an actual life situation. Without awareness of the goal, the individual's activity would have no meaning. The search for meaning is possible even when the individual's freedom is restricted. The search and implementation of the meaning of life is the most important motivation for the formation of human behavior and the development of the human personality. At the same time, D. A. Leontiev considers the meaning of his own life as "a more or less adequate experience of its orientation". He emphasizes that" from a psychological point of view, the main thing is not a conscious idea of the meaning of life, but the saturation of real everyday life with real meaning " [18]. We can say that human activity is associated with the search and realization of the meaning of life. It can be a search for a vector for life, or for the direction of movement in which the development of personality will be carried out. As well as the search for true values for which the person's life will be lived. The life-meaning will be the thing that subjectively brings moral satisfaction to each individual.

It should be noted, that a person is characterized by the presence of a number of meanings of life. The main one is "large", which remains almost unchanged. And many separate "small" ones being generated by each new situation. Thus, there is a certain hierarchy of meanings, values, and orientations. The content of the main meaning of life determines the content of all components of this hierarchy Moreover, when the ratio of meanings changes, the content of the meaning of life changes too. The dynamics of the hierarchical structure is determined by the individual and age features of a person, activity and social circumstances. The practice of working with parents raising children with early childhood autism as well as analysis of scientific literature made it possible to formulate a hypothesis that a change in the life situation, namely the appearance of a child with developmental disabilities in the family, changes the life meanings and hierarchies of value orientations of the child's parents

\section{Materials and methods}

To confirm this hypothesis, the following empirical tasks were outlined: -the revealing the peculiarities of life-meanings of parents raising children with ASD, -the studying of the change in the hierarchy of value orientations of parents after the birth of a child with developmental problems.

The study involved two groups of parents (each of 20 people). The empirical group included parents of children diagnosed with ASD. The control group consisted of parents of children without developmental disorders. The average age of parents in the empirical group was 37.5 years, and in the control group-34 years. All parents had children from 7 to 13 years old. To study the meaning of life of parents of a child with developmental problems, we used the questionnaire "Life-meaning orientations" (LMO), adapted by D.A. Leontiev's version of the "Purpose-in-Life Test" method by D. Krambo and L. Makholika (D.A. Leontiev, 2000). In order to study the changes in the structure of value orientations of parents after the birth of a child with developmental problems, we used the method of non-standardized self-report. They were asked to list those values in life that were important for them before and after the birth of children, in order of importance. Parents could be guided by the list of terminal values 
according to the method by M. Rokeach (M. Rokeach, 1973).

\section{Results}

The questionnaire LMO allows understanding what kind of life meanings dominate for the person: goals (future), process (present) or result (past), or all these components together [18]. In addition, the method allows evaluating the following characteristics: idea of the ability to control and manage own life. The results are shown in Table 1.

Table 1. Indicators of life-meaning orientations of parents.

\begin{tabular}{|l|c|c|}
\hline $\begin{array}{c}\text { Indicators of life-meaning } \\
\text { orientations }\end{array}$ & Empirical group & Control group \\
\hline 1.Goals in life & 33.8 & 33.4 \\
\hline 2.Life process & 29.75 & 28.14 \\
\hline 3.Life result & 26.93 & 26.05 \\
\hline 4.Locus of control "Me" & 21.92 & 20.76 \\
\hline 5.Locus of control "life" & 29.71 & 27.74 \\
\hline 6. Total & 142.12 & 136 \\
\hline
\end{tabular}

The results show that there were no significant differences between the empirical and control groups. For all indicators, we see the values being mean or slightly higher than the mean, although they are slightly higher in the empirical group than in the control group. This probably indicates that a person has goals in life, which give it meaningfulness, a time perspective, a confidence that not only the person's today life has a meaning, but the past part was also productive. Our respondents are confident that they will be able to build and control their lives in accordance with their own ideas about their meaning [18]. Any choice that a person makes is always based on their meaning sphere, life goals and orientation of the individual as a whole. The choice that the parents will make in a given situation, the goals they set, the actions they take, are largely determined by their value orientations, their ideas about the importance of a particular value. We can say that the life-meaning orientations of the parents of special children are their stable basis of personality, which allows them to preserve both their own meanings of life and to combine them with new ones.

During studying the changes in the structure of value orientations of parents after the birth of a child with developmental problems, they were asked to list those values in life that were important for them before and after the birth of children. It was not necessary to select all values from the list. In addition, the respondents could add those values in life that, in their opinion, were lacking in the proposed list. The ranked results are shown in Table 2.

Table 2. Ranked life values of parents.

\begin{tabular}{|l|c|c|c|c|}
\hline \multicolumn{1}{|c|}{ Values } & $\begin{array}{c}\text { Values rank } \\
\text { before the birth of } \\
\text { a child }\end{array}$ & & $\begin{array}{c}\text { Values ranks after } \\
\text { the birth of a } \\
\text { child }\end{array}$ & \\
\hline & Empirical gr. & Control gr. & Empirical gr. & Control gr. \\
\hline 1. Health care, & 5 & 5 & 4 & 4 \\
\hline $\begin{array}{l}\text { 2. Children } \\
\text { family. }\end{array}$ & 4 & 4 & 1 & 1 \\
\hline $\begin{array}{l}\text { 3. Career (work, } \\
\text { material support) }\end{array}$ & 2 & 2 & 3 & 2 \\
\hline $\begin{array}{l}\text { 4. Entertainment } \\
\text { (sports, } \\
\text { communication) }\end{array}$ & 1 & 1 & 2 & 3 \\
\hline $\begin{array}{c}\text { 5. Personal life } \\
\text { (happiness, "Me") }\end{array}$ & 3 & 3 & 5 & 5 \\
\hline
\end{tabular}


6. Comfort, protection, stability

As we can see, the structure of value orientations in both the first and the second groups is the same. The first are the values being typical for most young people and related to entertainment. They are followed by the values of career, personal life and the values associated with family and children are in fourth place only. The value of health was the least significant one for our respondents. This sequence of preferred values is common to many young people.

The birth of children results in a change in priorities, so the family, children and taking care of them come to the first place, but the following values change their significance for the parents of the empirical and control groups in different ways. For the respondents in the control group, the "work, career" category remained in the same second place as before the birth of children. As for parents from the empirical group, it moved into the third place, but at the same time, the value of "entertainment, communication, sports" became more significant. In our opinion, the significance of this value for this group is associated with a complete lack of communication and entertainment in their lives. The parents of the control group are characterized by a calm attitude to the values of "entertainment" and "health" (the 3rd-4th place, respectively). At the last place for both groups was the category of value orientations "personal life, happiness, "Me" (the fifth place). At the same time, parents raising an autistic child suddenly acquired such a vital value (also apparently vital) as "comfort, protection, stability". This confirms once again that families with children with disabilities are afraid of losing precisely these characteristics of their lives.

We were interested to find out why the parents moved the "personal life, happiness, "Me" category to the last place. The answer was unanimous: "That's how it should be." Apparently, the stereotypes prevailing in the society prescribe some kind of sacrifice in relation to own children. There is a "transition" from one responsibility to another in the periods before and after the birth of the child. At the same times the parents of healthy children are sure that the child will grow up and it will be possible to return to their goals and values, while the parents of a sick child realize the endlessness of this sacrifice and the impossibility of returning to another life. Undoubtedly, this aggravates the stressful situation in the family

\section{Conclusions}

Analyzing the peculiarities of life values of parents raising children with ASD, we saw that they use an arsenal of "unusual" life approaches and adaptations. In other words, they are in constant "combat readiness" and act as a fighter in a certain environment. Almost all parents from the empirical group admitted that they were not ready to tolerate "undeserved" remarks from passers-by and observers addressed to them and were able (even aggressively) to resist and defend their space. In addition, they are characterized by emotional instability and energy emptiness. They consider all their needs and desires unattainable and refer them to the "personal life section" as unrealizable fantasies or illusions. While the interests and health of the child are absolutely real, important and urgent. If parents solve problems from the positions "I must", "I am obliged", they has no motive of "I want, because ..." at all and the motive of "... what I want is feasible, because the child will remain such until the end of own life and this cannot be changed..." is unlikely. It turns out that, putting forward only the interests of the child and the child's health, parents reject their own interests and values. At the same time, the life-meaning orientations of the parents of special children are a stable basis of their personality, which allows them to preserve both their own meanings of life and to combine them with new ones. At the same time, the birth of a child with autism spectrum disorders results in a revision of the structure of the main value orientations of the parents. 
They emphasize the values of children and their health, and consider the values of personal life, and, especially, comfort and safety, to be the least important. People, mistakenly believing that nothing could be changed in their situation, must come to the conclusion, that they became one with fears, convinced themselves of helplessness, allowed themselves to deny development, abandoned new joyful opportunities. As a result, they do not see the road to joy and happiness. Meanwhile, awareness of own capabilities allows reconsideration of the significance of one's certain values, change own attitude to a hard situation and find a balance between own values and the goals and values of the child and family.

The obtained empirical data can be used in the practice of educational psychologists to provide psychological support to parents who have children with developmental problems.. The practice base is the development of self-help through the parents' understanding of goals of their own life, a revision of their attitude to themselves. Studying the life-meaning orientations of parents raising children with early childhood autism will help make programs of this kind more effective.

\section{References}

1. R.M. Hoffmann, Occupational Therapy and Children with Autism: A Look at What Occupational Therapy Is and a Review of Intervention Methods Used to Treat Children with Autism (The University of Arizona) http://hdl.handle.net/10150/146028 14/09/2020 17:07:13

2. I.I. Mamaichuk, E.V. Shabanova, Bulletin of the Leningrad State University named after A.S. Pushkin 1(5), 82-91 (2014) ISSN: 1818-66532014

3. E.M. Mastyukova, A.G. Moskovkina, Family education of children with developmental disabilities (Humanitarian publishing house Center VLADOS, M., 2004)

4. I.Y. Levchenko, V.V. Tkacheva, Psychological assistance to a family raising a child with developmental disabilities. Teacher edition (Prosveschenie, M., 2008)

5. T.N. Vysotina, Features of parental attitudes towards children with atypical autism. Author's abstract, cand. psychol. sciences (SPb., 2013)

6. D.G. Kulina, N.B. Yakovleva, Personality in a changing world: health, adaptation, development 1(4), 21-47 (2017) https://cyberleninka.ru/article/n/roditelskoeotnoshenie-k-detyam-s-rasstroystvami-autisticheskogo-spektra

7. T.X. Golden, Parents in relationships with their children with autism: a qualitative study: dis. ... Doctor of Philosophy (The University of Utah, 2012)

8. C. Rattaz, C. Michelon, H. Roeyers, A. Baghdadli, J Autism Dev Disord 47(9), 28262837 (2017)

9. C. Baeza-Velasco, C. Michelon, C. Rattaz, E. Pernon, A. Baghdadli, Journal of Developmental and Physical Disabilities 25, 613-624 (2013)

10. A.I. Sergienko, A.B. Kholmogorova, Counseling psychology and psychotherapy 2(27), 8-26 (2019) doi: 10.17759/cpp.2019270202

11. T.N. Kryukova, M.V. Saporovskaya, E.V. Kuftyak, Family psychology: life difficulties and coping with them (Rech, SPb, 2005)

12. M. Seligman, R. Darling, Ordinary families, special children (Terevinf, M., 2013)

13. E.A. Savina et al., Psychological assistance to parents in upbringing children with developmental problems. Educational psychologists' guide (Vlados, Moscow, 2008)

14. N.A. Ustinova, Pedagogy and psychology 6(24), 158-162 (2012)

15. N.L. Belopolskaya, N.A. Ulkina, Defectology 1 (2010) 
16. I.V. Abakumova, M.V. Godunov, Psychotherapy Bulletin 72(77), 113-131 (2019)

17. V.S. Mukhina, Personality: Myths and Reality (Alternative view. System approach. Innovative aspects) (Prometey, M., 2017)

18. D.A. Leontev, Mir psyhologii 1(77), 104-117 (2014) 